\title{
The profile of the bending mode band in solid $\mathrm{CO}_{2}$
}

\author{
G. A. Baratta and M. E. Palumbo
}

\begin{abstract}
INAF-Osservatorio Astrofisico di Catania, via Santa Sofia 78, 95123 Catania, Italy
e-mail: mepalumbo@oact.inaf.it
\end{abstract}

Received 6 April 2017 / Accepted 7 August 2017

\begin{abstract}
Context. Solid carbon dioxide $\left(\mathrm{CO}_{2}\right)$ is one of the most abundant species detected in icy grain mantles in dense molecular clouds. Its identification is based on the comparison between astronomical and laboratory spectra. In the past 30 yr the profile of solid $\mathrm{CO}_{2}$ infrared absorption bands has been extensively studied experimentally, however, the debate on the structure (amorphous versus crystalline) of $\mathrm{CO}_{2}$ samples obtained in laboratory by the thin-film technique is still open.

Aims. The aim of this work is to investigate if the presence of the double peak feature in the profile of the $\mathrm{CO}_{2}$ bending mode band is related to the crystalline or amorphous structure of the sample.

Methods. We performed new laboratory experiments depositing $\mathrm{CO}_{2}$ under ultra high vacuum (UHV) conditions at $17 \mathrm{~K}$. We investigated, using infrared transmission spectroscopy, the influence of various experimental parameters on the profile of the $\mathrm{CO}_{2}$ bands, namely deposition rate, sample thickness, annealing, and presence of $\mathrm{H}_{2} \mathrm{O}, \mathrm{CH}_{3} \mathrm{OH}$ or $\mathrm{CO}$ co-deposited with $\mathrm{CO}_{2}$.

Results. We found that, within experimental uncertainties, under UHV conditions the profile of the $\mathrm{CO}_{2}$ bands in pure solid samples does not depend on the deposition rate or the sample thickness in the ranges investigated. In all cases the bending mode band profile shows a double peak (at 660 and $655 \mathrm{~cm}^{-1}$ ). The spectra also show the Fermi resonance features that cannot be active in crystalline samples. On the other hand, when a small fraction of $\mathrm{H}_{2} \mathrm{O}$ or $\mathrm{CH}_{3} \mathrm{OH}$ is co-deposited with $\mathrm{CO}_{2}$ the double peak is not observed while it is observed when a $\mathrm{CO}_{2}: \mathrm{CO}$ mixture is considered. Furthermore, we measured the density of solid $\mathrm{CO}_{2}$ and the refractive index (at $543.5 \mathrm{~nm})$ at $17 \mathrm{~K}$ and at $70 \mathrm{~K}: \rho(17 \mathrm{~K})=1.17 \mathrm{~g} \mathrm{~cm}^{-3}, \rho(70 \mathrm{~K})=1.49 \mathrm{~g} \mathrm{~cm}^{-3}, n(17 \mathrm{~K})=1.285$, and $n(70 \mathrm{~K})=1.372$.

Conclusions. Our experimental results indicate that the presence of the double peak in the profile of the bending mode band is not an indication of a crystalline structure of the sample and they do not exclude the presence of amorphous solid $\mathrm{CO}_{2}$ in space.
\end{abstract}

Key words. astrochemistry - methods: laboratory: solid state - techniques: spectroscopic - ISM: molecules - solid state: volatile infrared: ISM

\section{Introduction}

Solid carbon dioxide $\left(\mathrm{CO}_{2}\right)$ is one of the most abundant species detected in icy grain mantles in dense molecular clouds. Its abundance with respect to $\mathrm{H}_{2} \mathrm{O}$ ranges between 10 and $50 \%$ towards different lines of sight (Gerakines et al. 1999; Nummelin et al. 2001; Pontoppidan et al. 2008; Boogert et al. 2015).

In the past $30 \mathrm{yr}$ the profile of solid $\mathrm{CO}_{2}$ bands has been extensively studied by many groups involved in the experimental investigation of astrophysical ice analogues (e.g. Sandford \& Allamandola 1990; Hudgins et al. 1993; Gerakines et al. 1995; Ehrenfreund et al. 1997a,b; Baratta \& Palumbo 1998; Palumbo et al. 1998; Dartois et al. 1999; Baratta et al. 2000; Palumbo \& Baratta 2000; Ioppolo et al. 2009, 2013; Isokoski et al. 2013; Sivaraman et al. 2013; Escribano et al. 2013; Gerakines \& Hudson 2015; Cooke et al. 2016). Previous studies are also available such as Wood \& Roux (1982) and Falk (1987).

Sandford \& Allamandola (1990) found that the mid-infrared spectrum of a thin $\mathrm{CO}_{2}$ film at $10 \mathrm{~K}$ shows five absorption bands, namely the ${ }^{12} \mathrm{CO}_{2}$ asymmetric stretching mode $\left(v_{3}\right)$ at about $2343 \mathrm{~cm}^{-1},{ }^{13} \mathrm{CO}_{2}$ asymmetric stretching mode at about $2283 \mathrm{~cm}^{-1},{ }^{12} \mathrm{CO}_{2}$ bending mode $\left(v_{2}\right)$ with a structured feature peaked at 660 and $655 \mathrm{~cm}^{-1}$, and combination modes $v_{1}+v_{3}$ and $2 v_{2}+v_{3}$ at $3707 \mathrm{~cm}^{-1}$ and $3600 \mathrm{~cm}^{-1}$, respectively. In their investigation, these authors also showed how the profile of the $\mathrm{CO}_{2}$ bands depends on the sample composition and temperature.
Their samples were obtained in a high vacuum chamber (base pressure of about $3 \times 10^{-8} \mathrm{mbar}$ ) and typically deposited on a CsI substrate at a rate of about $2 \mu \mathrm{m} / \mathrm{h}$. Transmission infrared spectra were taken at normal incidence; that is the IR beam was perpendicular to the surface of the sample.

The $v_{1}$ symmetric stretching vibration, which occurs at about $1385 \mathrm{~cm}^{-1}$, is infrared inactive. However, thick $\mathrm{CO}_{2}$ samples show two features at about $1385 \mathrm{~cm}^{-1}$ and at about $1280 \mathrm{~cm}^{-1}$. These features are assigned to the $v_{1}$ mode in Fermi resonance with the $2 v_{2}$ (overtone) mode (Falk 1987; Sivaraman et al. 2013; Gerakines \& Hudson 2015).

Baratta \& Palumbo (1998) showed that when transmission spectra of pure $\mathrm{CO}_{2}$ solid samples are taken at oblique incidence the $v_{3}$ band profile shows an additional feature at about $2378 \mathrm{~cm}^{-1}$ and the $v_{2}$ band profile shows an additional feature at about $675 \mathrm{~cm}^{-1}$. This occurrence is referred to as the longitudinal optical-transverse optical (LO-TO) splitting. When a polarizer is placed in the path of the IR beam of the spectrometer it is possible to acquire spectra with the electric vector parallel to the plane of incidence (P polarization) and spectra with the electric vector perpendicular to the plane of incidence (S polarization). Baratta \& Palumbo (1998) showed that the LO-TO splitting is observed in P polarization spectra while only the TO modes are present in $\mathrm{S}$ polarization spectra.

When thin films of pure $\mathrm{CO}_{2}$ are analysed by reflection absorption infrared spectroscopy, for both $v_{3}$ and $v_{2}$ bands only the 
LO mode is detected, while thick films show both the LO and TO modes (e.g. Escribano et al. 2013; Cooke et al. 2016).

Isokoski et al. (2013) performed a detailed study of the $\mathrm{CO}_{2}$ band profiles recording transmission spectra at resolution $0.1 \mathrm{~cm}^{-1}$. In their experiments the growth rate is determined by setting the exposure to $\sim 10^{16}$ molecules $\mathrm{cm}^{-2} \mathrm{~s}^{-1}$. Assuming a density value of $1.17 \mathrm{~g} \mathrm{~cm}^{-3}$ (this work) this corresponds to about $22 \mu \mathrm{m} / \mathrm{h}$.

Recently, former experimental results have been questioned by Gerakines \& Hudson (2015). They have found that the $\mathrm{CO}_{2}$ bending mode band shows the double peak structure when the sample is obtained with a high deposition rate $(>0.2 \mu \mathrm{m} / \mathrm{h})$, while they do not observe the double peak when the sample is obtained with a low deposition rate $(\sim 0.1 \mu \mathrm{m} / \mathrm{h})$. Based on these experimental results they have claimed that in the former case a crystalline sample is obtained, while in the latter case the sample is amorphous and they have concluded that all previous studies have dealt with crystalline $\mathrm{CO}_{2}$ samples since a high deposition rate has been adopted.

Other authors have investigated the properties of $\mathrm{CO}_{2}$ monomers and dimers trapped in various matrices (such as $\mathrm{Ar}$ and $\mathrm{N}_{2}$ ) at cryogenic temperatures (e.g. Vigasin et al. 2000; Gómez Castaño et al. 2008). In fact weak intermolecular interaction between carbon dioxide molecules results in the formation of van der Waals complexes or dimers. These studies have shown that in a monomer, the $v_{2}$ bending mode is doubly degenerate. In a dimer, this mode splits into four vibrations. Of these, two vibrations, one in-plane and one out-of-plane, are active in infrared absorption (Vigasin et al. 2000). In their work, Gómez Castaño et al. (2008) assigned the band peaked at $1384.1 \mathrm{~cm}^{-1}$, observed when $\mathrm{CO}_{2}$ is diluted in $\mathrm{Ar}$ matrix, to the $\mathrm{CO}_{2}$ symmetric stretching mode in the dimer. As predicted by theoretical calculations, this mode, which is IR silent in the monomer, is slightly activated in the dimeric structure. The other band at $1278.9 \mathrm{~cm}^{-1}$ is attributed to the overtone of the bending mode, which is affected by Fermi resonance. These authors also observed these doublet for the $\left(\mathrm{CO}_{2}\right)_{2}$ isolated in $\mathrm{N}_{2}$ matrices at 1384.5 and $1279.2 \mathrm{~cm}^{-1}$, respectively.

To further analyse the profile of the band in pure solid $\mathrm{CO}_{2}$ and the structure of the corresponding $\mathrm{CO}_{2}$ samples here we performed new experiments depositing $\mathrm{CO}_{2}$ under ultra high vacuum (UHV) conditions. We investigated, using infrared transmission spectroscopy, the influence of different experimental parameters, namely the deposition rate, sample thickness, annealing, and presence of $\mathrm{H}_{2} \mathrm{O}, \mathrm{CH}_{3} \mathrm{OH}$ or $\mathrm{CO}$ co-deposited with $\mathrm{CO}_{2}$.

\section{Experimental methods}

We obtained the experimental results presented here at the Laboratorio di Astrofisica Sperimentale at INAF-Osservatorio Astrofisico di Catania (Italy). The experiments were performed in a stainless steel UHV chamber with a base pressure better than $10^{-9}$ mbar. A closed-cycle helium cryostat is attached to the UHV chamber for cooling the substrate. The cryostat is protected by a copper shield kept at $77 \mathrm{~K}$. An infrared transparent substrate $(\mathrm{KBr})$ is placed in thermal contact with the final tail of the cryostat and its temperature can be varied between $17 \mathrm{~K}$ and $300 \mathrm{~K}$.

The vacuum chamber is placed in the sample compartment of a Fourier transform infrared spectrometer (Bruker Vertex 70) and transmission spectra of the sample are acquired in the range $7800-400 \mathrm{~cm}^{-1}(1.3-25 \mu \mathrm{m})$ at a resolution of $1 \mathrm{~cm}^{-1}$ with a sampling of $0.25 \mathrm{~cm}^{-1}$. The substrate forms an angle of $45^{\circ}$ with

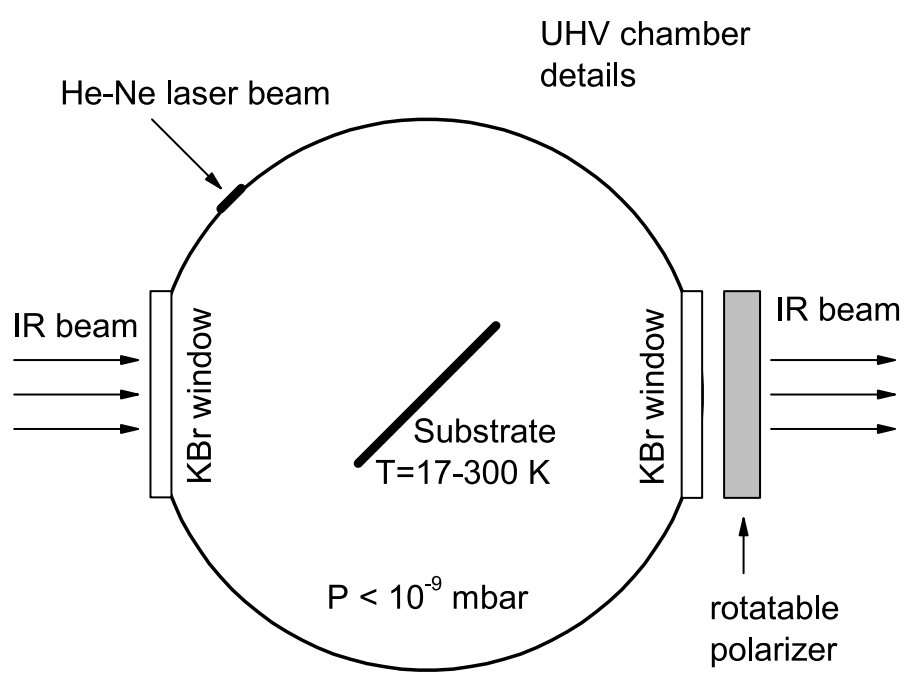

Fig. 1. Schematic depiction of the ultra high vacuum chamber.

respect to the IR beam. A schematic view of the vacuum chamber is presented in Fig. 1.

Gas or gas mixtures can be admitted into the main chamber by means of a needle valve. Because of the cold surface of the substrate, gas (or mixtures) are subsequently deposited as solids. The gas inlet is not directed towards the substrate, thus a background deposition is obtained. This method has the advantage that the film deposited has a uniform thickness but has the disadvantage that gas phase molecules can freeze out onto all cold surfaces inside the chamber. To avoid any deposition on the backside of the substrate, this is protected by a $2 \mathrm{~cm}$ long copper tube aligned with the IR beam and with the central hole with a diameter of about $4 \mathrm{~mm}$.

A He-Ne laser $(\lambda=543.5 \mathrm{~nm})$ is used to monitor the sample thickness on the substrate during accretion. This is achieved by looking at the interference pattern (intensity versus time) given by the laser beam reflected at near normal incidence $\left(2.9^{\circ}\right)$ by the vacuum-film and film-substrate interfaces. More details on this procedure can be found in Baratta \& Palumbo (1998), Fulvio et al. (2009), Modica \& Palumbo (2010), and Urso et al. (2016).

A rotatable polarizer is placed in the path of the IR beam, which enables us to subsequently record spectra in P mode, in which the electric vector is parallel to the plane of incidence, and $\mathrm{S}$ mode, in which the electric vector is perpendicular to the plane of incidence. The plane of incidence is the plane of the paper in Fig. 1. Background spectra are recorded at the start of the measurement before sample deposition in both modes and subsequently each spectrum is divided by the background spectrum acquired in the same polarization mode.

A list of the new experiments performed in this work is given in Table 1. Aldrich Chemical 99.8\% $\mathrm{CO}_{2}, 99.0 \%$ $\mathrm{CO}$, Sigma Aldrich Chromasolv Plus $\mathrm{H}_{2} \mathrm{O}$, and Merck 99.8\% $\mathrm{CH}_{3} \mathrm{OH}$ were used to prepare the samples. The $\mathrm{CO}_{2}: \mathrm{X}$ ratio in samples numbered from 6 to 9 in Table 1 is determined on the basis of previous calibration experiments and this ratio resulted to be consistent with the column density ratio estimated from the spectra adopting $\mathrm{A}\left(\mathrm{CO}_{2}, 2340\right)=$ $7.6 \times 10^{-17} \mathrm{~cm} \mathrm{~mol}^{-1}$ (Yamada \& Person 1964), $\mathrm{A}\left(\mathrm{CO}_{2}, 660\right)=$ $1.1 \times 10^{-17} \mathrm{~cm} \mathrm{~mol}^{-1}$ (Gerakines et al. 1995), $\mathrm{A}\left(\mathrm{H}_{2} \mathrm{O}, 1660\right)=$ $1 \times 10^{-17} \mathrm{~cm} \mathrm{~mol}^{-1}$ (Hudgins et al. 1993), $\mathrm{A}(\mathrm{CO})=1.1 \times$ $10^{-17} \mathrm{~cm} \mathrm{~mol}^{-1}$ (Jiang et al. 1975), and $\mathrm{A}\left(\mathrm{CH}_{3} \mathrm{OH}, 1020\right)=$ $1.3 \times 10^{-17} \mathrm{~cm} \mathrm{~mol}^{-1}$ (Palumbo et al. 1999). Figure 2 shows the 
Table 1. New experiments performed in this work.

\begin{tabular}{clccc}
\hline \hline $\begin{array}{c}\text { Sample } \\
\text { no. }\end{array}$ & Composition & $\begin{array}{c}\text { Deposition rate } \\
(\mu \mathrm{m} / \mathrm{h})\end{array}$ & $\begin{array}{c}\text { Thickness } \\
(\mu \mathrm{m})\end{array}$ & $\begin{array}{c}\text { Bending mode } \\
\text { double peak }\end{array}$ \\
\hline 1 & pure $\mathrm{CO}_{2}$ & 0.110 & 0.150 & yes \\
2 & pure $\mathrm{CO}_{2}$ & 0.065 & 0.125 & yes \\
3 & pure $\mathrm{CO}_{2}$ & 0.100 & 0.652 & yes \\
4 & pure $\mathrm{CO}_{2}$ & 0.100 & 0.143 & yes \\
5 & pure $\mathrm{CO}_{2}$ & 0.076 & 0.108 & yes \\
6 & $\mathrm{CO}_{2}: \mathrm{H}_{2} \mathrm{O}=12: 1$ & 0.067 & 0.122 & no \\
7 & $\mathrm{CO}_{2}: \mathrm{H}_{2} \mathrm{O}=12: 1$ & 0.950 & 0.123 & no \\
8 & $\mathrm{CO}_{2}: \mathrm{CO}=8: 1$ & 0.107 & 0.155 & yes \\
9 & $\mathrm{CO}_{2}: \mathrm{CH} \mathrm{OH}=11: 1$ & 0.112 & 0.149 & no \\
\hline
\end{tabular}

Notes. All samples were deposited at $17 \mathrm{~K}$ other than sample No. 5, which was deposited at $70 \mathrm{~K}$.

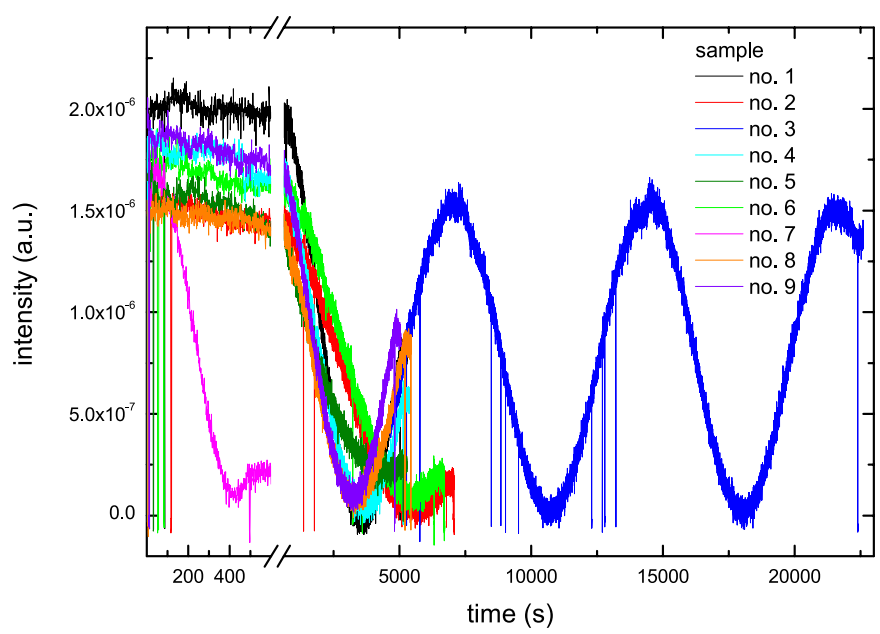

Fig. 2. Interference curves acquired during deposition of all the samples studied in this work.

interference curves acquired during deposition of all the samples studied in this work.

\section{Results}

\subsection{Refractive index and density measurement}

From the interference curve obtained during deposition of sample No. 3 (final thickness equal to $0.652 \mu \mathrm{m}$ ) it has been possible to calculate the refractive index of solid $\mathrm{CO}_{2}$ (at $543.5 \mathrm{~nm}$ ) and its density at $17 \mathrm{~K}$. In fact the amplitude of the experimental interference curve depends on the refractive index $n_{\mathrm{f}}$ of the species at laser wavelength, the refractive index $n_{\mathrm{s}}$ of the substrate, the incidence angle $\theta_{\mathrm{i}}$ of the laser beam, and the polarization of the laser light. Hence, because all the other quantities are known, $n_{\mathrm{f}}$ can be derived, using numerical methods, from the measured amplitude of the experimental interference curve (intensity ratio between maxima and minima). This was achieved via a program, written in Fortran language (Baratta \& Palumbo 1998) ${ }^{1}$. The value we obtained is $n_{\mathrm{CO}_{2}}=1.285$ at $543.5 \mathrm{~nm}$.

\footnotetext{
1 A free web interface that allows the online use of the program is available at http://www. oact.inaf.it/thickness/ (Urso et al. 2016).
}

From the derived $n_{\mathrm{f}}$ value, we estimated the film density using the Lorentz-Lorenz relation. In particular, for a given species the Lorentz-Lorenz coefficient, $L$, is nearly constant for a fixed wavelength regardless of the material phase and temperature (Wood \& Roux 1982). This quantity is related to the density $(\rho)$ by the Lorentz-Lorenz relation

$L \rho=\frac{n_{\mathrm{f}}^{2}-1}{n_{\mathrm{f}}^{2}+2}$.

Adopting $L=0.153 \mathrm{~cm}^{3} / \mathrm{g}$, we obtained $\rho\left(\mathrm{CO}_{2}\right)=1.17 \mathrm{~g} \mathrm{~cm}^{-3}$ at $17 \mathrm{~K}$. The value $L=0.153 \mathrm{~cm}^{3} / \mathrm{g}$ was obtained from the refractive index at $543.5 \mathrm{~nm}(n=1.0004504)$ measured at standard conditions $\left(0{ }^{\circ} \mathrm{C}\right.$ and 760 Torr) as reported by Polyanskiy (2017). Recently, Loeffler et al. (2016) have presented a detailed study on the effects of the deposition technique on the measurements of the visible $(\lambda=670 \mathrm{~nm})$ refractive index and the density of solid $\mathrm{CO}_{2}$. Fitting their experimental data they have found that the Lorentz-Lorenz coefficient values $L=0.148 \pm 0.006 \mathrm{~cm}^{3} / \mathrm{g}$. Neglecting the small differences in the value of $L$ due to the different wavelength, the value obtained by Loeffler et al. (2016) is, within uncertainties, equal to the value obtained from gas phase measurements, confirming that the Lorentz-Lorenz coefficient is nearly constant regardless of the material phase and temperature.

Following the same procedure, from the interference curve obtained during deposition of sample No. 5, we estimated the refractive index of solid $\mathrm{CO}_{2}$ (at $543.5 \mathrm{~nm}$ ) and its density at $70 \mathrm{~K}$. We found $n_{\mathrm{CO}_{2}}=1.372$ and $\rho\left(\mathrm{CO}_{2}\right)=1.49 \mathrm{~g} \mathrm{~cm}^{-3}$.

We point out that different values of the density and refractive index for solid $\mathrm{CO}_{2}$ have been reported in the literature. Satorre et al. (2008) measured the density and refractive index (at $632.8 \mathrm{~nm}$ ) of $\mathrm{CO}_{2}$ at various temperatures (from $10 \mathrm{~K}$ to its sublimation temperature) and found that the density varies from $0.98 \mathrm{~g} \mathrm{~cm}^{-3}$ (at $10 \mathrm{~K}$ ) to $1.5 \mathrm{~g} \mathrm{~cm}^{-3}$, while the refractive index varies from 1.21 to 1.35 . Wood \& Roux (1982) measured a density value of $1.08 \mathrm{~g} \mathrm{~cm}^{-3}$ and refractive index (at $632.8 \mathrm{~nm}$ ) equal to 1.27 at $20 \mathrm{~K}$. Loeffler et al. (2016) have found that at $14 \mathrm{~K}$ the refractive index varies in the range 1.27-1.31 and the density varies in the range $1.18-1.38 \mathrm{~g} \mathrm{~cm}^{-3}$ depending on the deposition technique. As pointed out by Loeffler et al. (2016), it is not surprising that different measurements result in different values. In fact the density and in turn the refractive index of a solid sample in some instances strongly depend on the experimental conditions such as temperature, growth angle, and deposition rate 

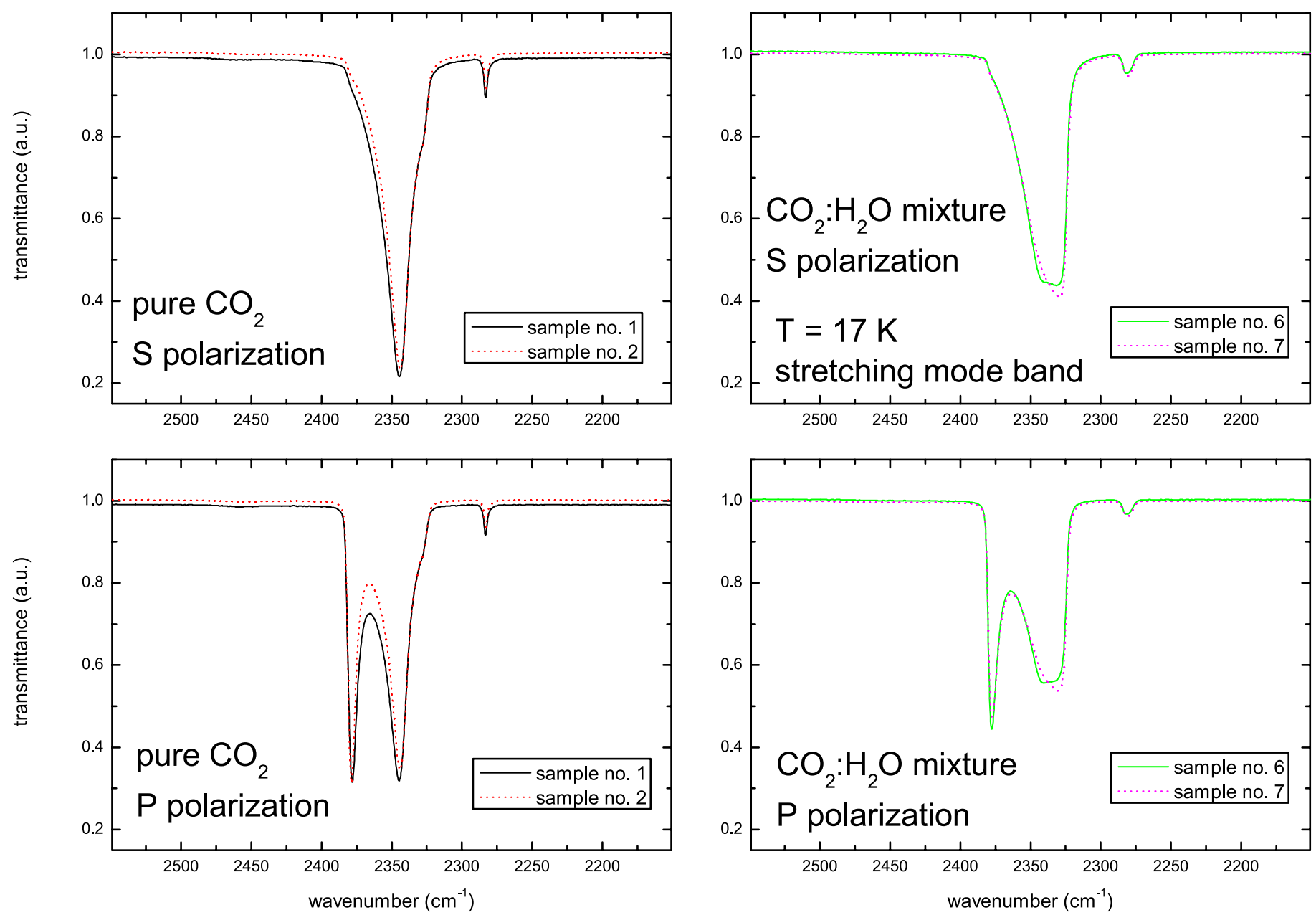

Fig. 3. Stretching mode band of $\mathrm{CO}_{2}$ in pure solid $\mathrm{CO}_{2}$ and $\mathrm{CO}_{2}: \mathrm{H}_{2} \mathrm{O}$ mixtures. Spectra are taken at $17 \mathrm{~K}$ and are shown in transmittance scale.

(e.g. Hagen et al. 1983; Jenniskens \& Blake 1994; Kimmel et al. 2001a,b; Dohnálek et al. 2003).

\subsection{Pure $\mathrm{CO}_{2}$ and $\mathrm{CO}_{2}: \mathrm{H}_{2} \mathrm{O}$ mixtures}

Figure 3 shows the profile of the stretching mode band of samples 1,2 (pure solid $\left.\mathrm{CO}_{2}\right), 6$, and $7\left(\mathrm{CO}_{2}: \mathrm{H}_{2} \mathrm{O}\right.$ mixtures) in $\mathrm{P}$ and $\mathrm{S}$ polarization. For samples Nos. 1 and 2 (pure solid $\mathrm{CO}_{2}$ ), spectra taken in $\mathrm{S}$ polarization (top panel) show a band centred at about $2345 \mathrm{~cm}^{-1}$ that is assigned to the asymmetric stretching mode $\left(v_{3}\right)$ of ${ }^{12} \mathrm{CO}_{2}$ and a band centred at about $2283 \mathrm{~cm}^{-1}$ that is assigned to the asymmetric stretching mode of ${ }^{13} \mathrm{CO}_{2}$. Spectra taken in $\mathrm{P}$ polarization (bottom panel) show an additional band centred at about $2378 \mathrm{~cm}^{-1}$ that is assigned to the LO mode of the ${ }^{12} \mathrm{CO}_{2}$ asymmetric stretching mode. As discussed by Baratta \& Palumbo (1998), Palumbo \& Baratta (2000), Palumbo et al. (2006), and Urso et al. (2016) when transmission spectra are taken at oblique incidence, spectra in $\mathrm{P}$ polarization show the LO-TO splitting while spectra taken in S polarization, for symmetry reasons, are equivalent to spectra taken at normal incidence and only show the TO mode. When a small amount of $\mathrm{H}_{2} \mathrm{O}$ is present in the mixture (i.e. samples Nos. 6 and 7) the peak position of the $v_{3}$ band shifts to $2330 \mathrm{~cm}^{-1}$ and the band is broader (panels on the right-hand side of Fig. 3).

Figure 4 shows the profile of the bending mode band of samples $1,2,3$ (pure solid $\left.\mathrm{CO}_{2}\right), 6$, and $7\left(\mathrm{CO}_{2}: \mathrm{H}_{2} \mathrm{O}\right.$ mixtures) in $\mathrm{P}$ and $\mathrm{S}$ polarization. For samples Nos. 1, 2, and 3 (i.e. pure solid $\mathrm{CO}_{2}$ ) spectra taken in $\mathrm{S}$ polarization (top panel) show a double peak band centred at 660 and $655 \mathrm{~cm}^{-1}$ that is assigned to the bending mode $\left(v_{2}\right)$ of ${ }^{12} \mathrm{CO}_{2}$ and a band centred at about $639 \mathrm{~cm}^{-1}$ that is assigned to the bending mode of ${ }^{13} \mathrm{CO}_{2}$. Spectra taken in $\mathrm{P}$ polarization (bottom panel) show an additional band centred at about $675 \mathrm{~cm}^{-1}$ that is assigned to the LO mode of the ${ }^{12} \mathrm{CO}_{2}$ bending mode. For samples Nos. 6 and 7 (i.e. $\mathrm{CO}_{2}: \mathrm{H}_{2} \mathrm{O}$ mixtures) spectra taken in $\mathrm{S}$ polarization (top panel) show a single peak band centred at $655 \mathrm{~cm}^{-1}$ that is assigned to the bending mode $\left(v_{2}\right)$ of ${ }^{12} \mathrm{CO}_{2}$. Spectra taken in $\mathrm{P}$ polarization (bottom panel) show an additional band centred at about $675 \mathrm{~cm}^{-1}$ that is assigned to the LO mode of the ${ }^{12} \mathrm{CO}_{2}$ bending mode.

Figure 5 shows the spectral range $4000-2800 \mathrm{~cm}^{-1}$ for samples No. 2 (pure solid $\left.\mathrm{CO}_{2}\right)$ and No. $6\left(\mathrm{CO}_{2}: \mathrm{H}_{2} \mathrm{O}\right.$ mixture). These samples have the same thickness $(\simeq 0.12 \mu \mathrm{m})$. The spectrum of sample No. 2 shows two features at 3708 and $3600 \mathrm{~cm}^{-1}$ easily assigned to the $v_{1}+v_{3}$ and $2 v_{2}+v_{3}$ combination modes (e.g. Sandford \& Allamandola 1990) of solid $\mathrm{CO}_{2}$. The spectrum of sample No. 6 shows two features at 3704 and $3597 \mathrm{~cm}^{-1}$ that are less intense and broader with respect to the corresponding features in sample No. 2. These differences can be ascribed to the presence of $\mathrm{H}_{2} \mathrm{O}$ in sample No. 6. It is important to note that none of the spectra show the feature due to polymeric water at about $3300 \mathrm{~cm}^{-1}$.

Figure 6 shows the spectral range $1530-1180 \mathrm{~cm}^{-1}$ for sample No. 3 (thick pure solid $\mathrm{CO}_{2}$ ). This spectrum clearly shows two features at $1384 \mathrm{~cm}^{-1}$ and at about $1278 \mathrm{~cm}^{-1}$. These features are assigned to the $v_{1}$ (symmetric stretching 
G. A. Baratta and M. E. Palumbo: Profile of $\mathrm{CO}_{2}$ bands
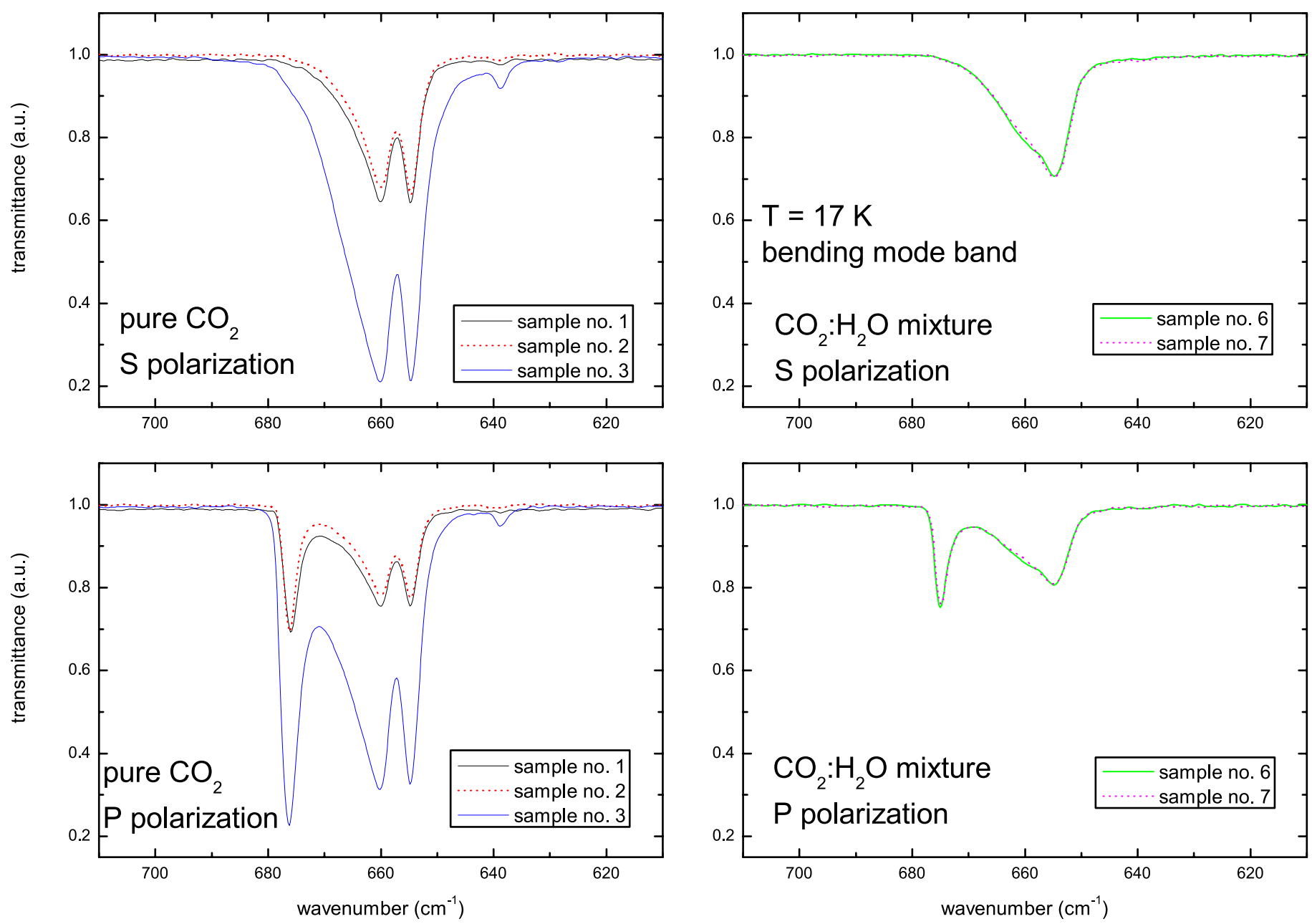

Fig. 4. Bending mode band of $\mathrm{CO}_{2}$ in pure solid $\mathrm{CO}_{2}$ and $\mathrm{CO}_{2}: \mathrm{H}_{2} \mathrm{O}$ mixtures. Spectra, acquired at $17 \mathrm{~K}$, are shown in transmittance scale.

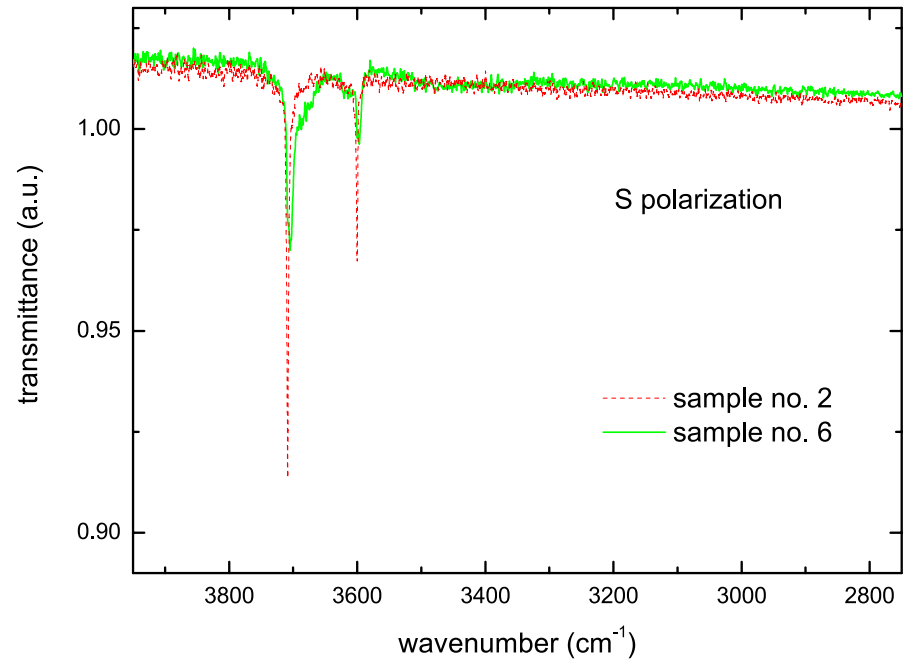

Fig. 5. Transmittance spectra of samples Nos. 2 and 6 in the 4000$2800 \mathrm{~cm}^{-1}$ spectral region. Spectra are acquired at $17 \mathrm{~K}$.

vibration) mode in Fermi resonance with the $2 v_{2}$ (overtone) mode (Falk 1987). According to previous studies, these features are observed in amorphous samples while they are not detected in crystalline samples (Falk 1987; Sivaraman et al. 2013; Gerakines \& Hudson 2015).

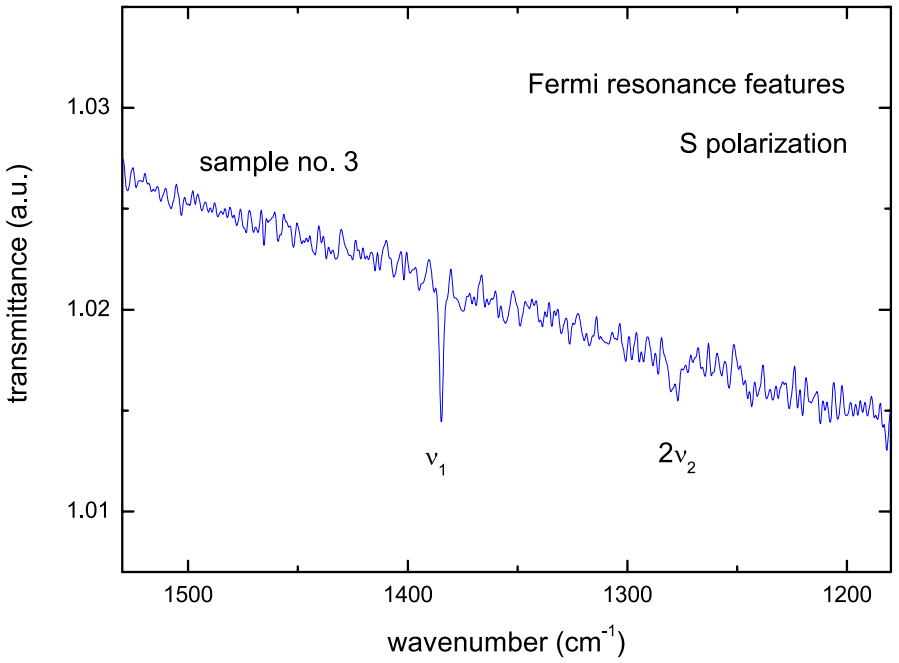

Fig. 6. Fermi resonance features for sample No. 3 (thick pure $\mathrm{CO}_{2}$ ). The spectrum is acquired at $17 \mathrm{~K}$ and is shown in transmittance scale.

\section{3. $\mathrm{CO}_{2}: \mathrm{CO}$ and $\mathrm{CO}_{2}: \mathrm{CH}_{3} \mathrm{OH}$ mixtures}

In order to further investigate the behaviour of $\mathrm{CO}_{2}$ when a small fraction of $\mathrm{H}_{2} \mathrm{O}(\mu=1.85$ debye $)$ is present in the sample, we analysed mixtures with $\mathrm{CO}(\mu=0.12$ debye $)$ and $\mathrm{CH}_{3} \mathrm{OH}$ $(\mu=1.69$ debye). Figure 7 shows the profile of the asymmetric 

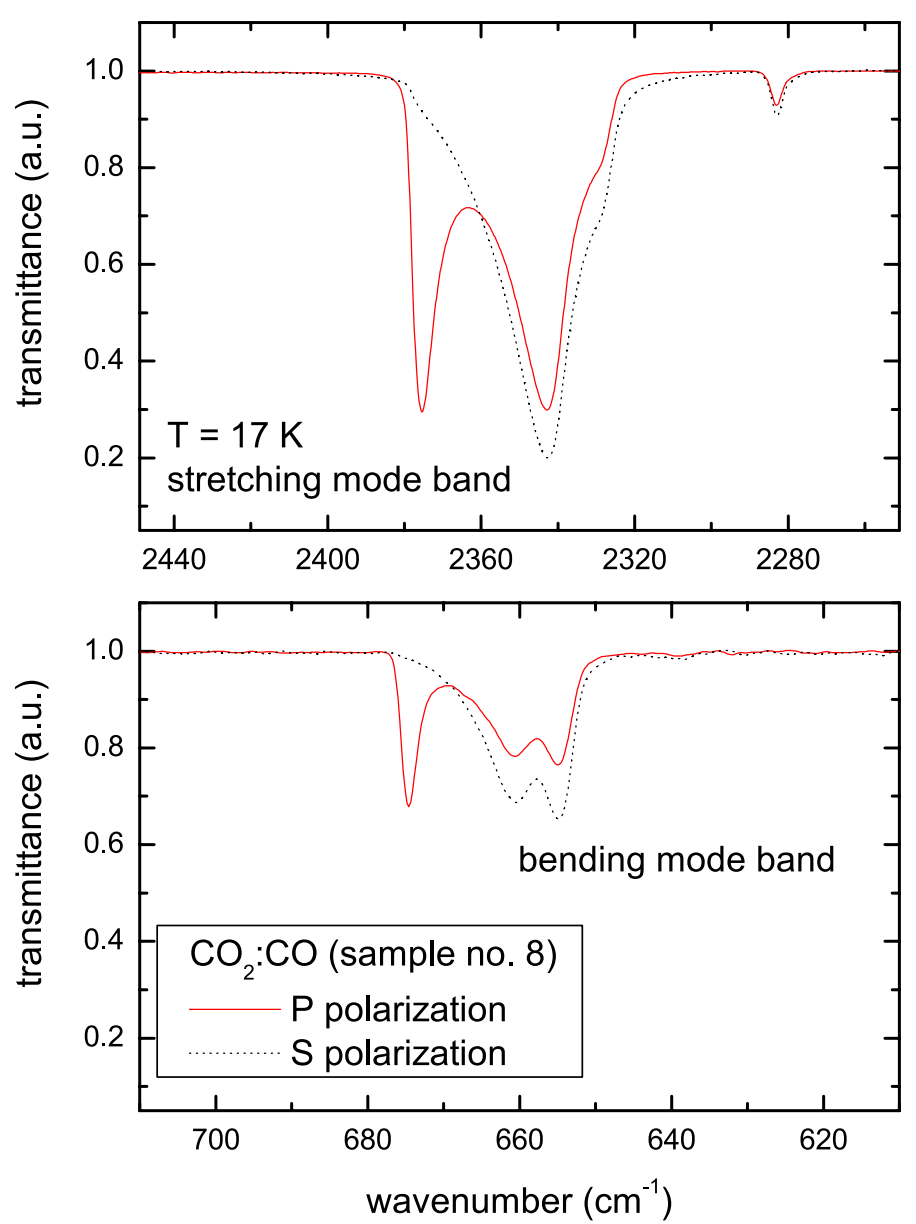

Fig. 7. Transmittance spectra of sample No. $8\left(\mathrm{CO}_{2}: \mathrm{CO}=8: 1\right.$ mixture $)$ in the 2450-2250 $\mathrm{cm}^{-1}$ spectral region (top panel) and in the 710$610 \mathrm{~cm}^{-1}$ spectral region (bottom panel). Spectra are acquired at $17 \mathrm{~K}$.

stretching mode and the bending mode bands in a $\mathrm{CO}_{2}: \mathrm{CO}=$ 8:1 mixture at $17 \mathrm{~K}$. The asymmetric stretching mode band peaks at $2343 \mathrm{~cm}^{-1}$ (TO mode) and the LO mode observed in P-polarization spectra peaks at $2375 \mathrm{~cm}^{-1}$. The profile of the bending mode band shows a double peak (660 and $655 \mathrm{~cm}^{-1}$ ) and in P-polarization spectra the LO mode peaks at $675 \mathrm{~cm}^{-1}$. In this mixture the profile of the $\mathrm{CO}_{2}$ bands is very similar to the profile of the same bands in pure $\mathrm{CO}_{2}$ sample (see Figs. 3 and 4).

Figure 8 shows the profile of the asymmetric stretching mode and the bending mode bands in a $\mathrm{CO}_{2}: \mathrm{CH}_{3} \mathrm{OH}=11: 1$ mixture. In the spectrum taken after sample deposition at $17 \mathrm{~K}$ ( $\mathrm{S}$ polarization) the asymmetric stretching mode band peaks at $2330 \mathrm{~cm}^{-1}$ and the LO mode observed in the spectrum taken in $\mathrm{P}$ polarization peaks at $2376 \mathrm{~cm}^{-1}$; the bending mode band does not show (at $17 \mathrm{~K}$ ) the double peak structure and peaks at $655 \mathrm{~cm}^{-1}$ and the LO mode peaks at $674 \mathrm{~cm}^{-1}$. In this case the profile of the $\mathrm{CO}_{2}$ bands is very similar to the profile of the same bands in a $\mathrm{CO}_{2}: \mathrm{H}_{2} \mathrm{O}=12: 1$ mixture (see Figs. 3 and 4).

\subsection{Thermal annealing}

Figure 9 presents the profile of $\mathrm{CO}_{2}$ asymmetric stretching and bending mode bands for a sample of pure $\mathrm{CO}_{2}$ (sample No. 4) deposited at $17 \mathrm{~K}$, warmed up to $77 \mathrm{~K}$, and cooled down the 17 K. Similar to the results presented by other authors (e.g. Sandford \& Allamandola 1990; Isokoski et al. 2013), the figure shows that both band profiles become narrower and deeper upon thermal annealing while no changes are observed when the sample is cooled down to $17 \mathrm{~K}$. In fact the spectra (both $\mathrm{P}$ and $\mathrm{S}$ polarization) taken after the sample is cooled down to $17 \mathrm{~K}$ are indistinguishable from the respective spectra taken at $77 \mathrm{~K}$.

Figure 10 presents the profile of $\mathrm{CO}_{2}$ asymmetric stretching and bending mode bands for a sample of pure $\mathrm{CO}_{2}$ (sample No. 5) deposited at $70 \mathrm{~K}$, warmed up to $77 \mathrm{~K}$, and cooled down to $17 \mathrm{~K}$. The spectra shown (both $\mathrm{P}$ and $\mathrm{S}$ polarization) are indistinguishable from each other.

These results indicate that the structure of the $\mathrm{CO}_{2}$ sample deposited at $17 \mathrm{~K}$ is amorphous (unstable) and evolves, upon annealing, to a stable crystalline structure that is not further modified when the sample is cooled down. On the other hand, the sample deposited at $70 \mathrm{~K}$ does not show any variation upon thermal cycles suggesting that the sample deposited at $70 \mathrm{~K}$ has a stable crystalline structure. A similar behaviour has been observed for other solid phase molecules (e.g. Hudgins et al. 1993; Leto \& Baratta 2003). The difference between the structure of the sample deposited at $17 \mathrm{~K}$ and that of the sample deposited at $70 \mathrm{~K}$ is also testified by the different values of the refractive index and density measured (see Sect. 3.1).

Figure 8 shows the profile of the $\mathrm{CO}_{2}$ bands when a $\mathrm{CO}_{2}: \mathrm{CH}_{3} \mathrm{OH}$ mixture (sample No. 9) deposited at $17 \mathrm{~K}$ is warmed up to $77 \mathrm{~K}$ and then cooled down to $17 \mathrm{~K}$. In this case, upon thermal annealing, the profile of the $\mathrm{CO}_{2}$ bands significantly changes. At $77 \mathrm{~K}$ the stretching mode band and the bending mode band profiles both shift to higher wave numbers and become narrower. Furthermore, the profile of the bending mode band splits into two components. When the sample is cooled down to $17 \mathrm{~K}$ it is not further modified and the spectra taken at $17 \mathrm{~K}$ (both $\mathrm{P}$ and $\mathrm{S}$ polarization) are indistinguishable from the respective spectra taken at $77 \mathrm{~K}$.

\section{Discussion}

The experimental results presented here indicate that when pure $\mathrm{CO}_{2}$ is deposited on a cold substrate at low temperature in a UHV chamber the IR spectrum simultaneously shows the Fermi resonance features and the double peak of the bending mode band profile. As discussed by Falk (1987), Sivaraman et al. (2013), and Gerakines \& Hudson (2015), the Fermi resonance features are observed in amorphous samples while they are not detected in crystalline samples. As a consequence the IR spectrum of amorphous pure solid $\mathrm{CO}_{2}$ shows the double peak of the bending mode band profile. The double peak profile disappears when or a small amount of $\mathrm{CH}_{3} \mathrm{OH}$ or a small amount of $\mathrm{H}_{2} \mathrm{O}$ (as small as $10 \%$ ), which is not detectable by the band at $3300 \mathrm{~cm}^{-1}$ assigned to polymeric water, is co-deposited with $\mathrm{CO}_{2}$ (as shown in Figs. 4 and 8). $\mathrm{H}_{2} \mathrm{O}$ and $\mathrm{CH}_{3} \mathrm{OH}$ are polar molecules (dipole moment equal to 1.85 and 1.69 debye, respectively); our results show that when a small amount of an apolar molecule (such as $\mathrm{CO}, \mu=0.12$ debye) is co-deposited with $\mathrm{CO}_{2}$ the profile of the $\mathrm{CO}_{2}$ bands does not change significantly.

Öberg et al. (2007) have studied the effects of $\mathrm{CO}_{2}$ on $\mathrm{H}_{2} \mathrm{O}$ band profiles and band strength values in solid $\mathrm{H}_{2} \mathrm{O}: \mathrm{CO}_{2}$ mixtures and have found that the band strength of the $\mathrm{OH}$ stretching mode (at about $3300 \mathrm{~cm}^{-1}$ ) decreases as much as an order of magnitude from a sample of pure $\mathrm{H}_{2} \mathrm{O}$ to a $\mathrm{H}_{2} \mathrm{O}: \mathrm{CO}_{2}=1: 4$ solid sample. They have not reported the results for mixtures with a lesser abundance of $\mathrm{H}_{2} \mathrm{O}$ mixed with $\mathrm{CO}_{2}$ but, from the decreasing trend reported, it is reasonable to assume that the band strength of the $\mathrm{OH}$ stretching mode band would further decrease 
G. A. Baratta and M. E. Palumbo: Profile of $\mathrm{CO}_{2}$ bands
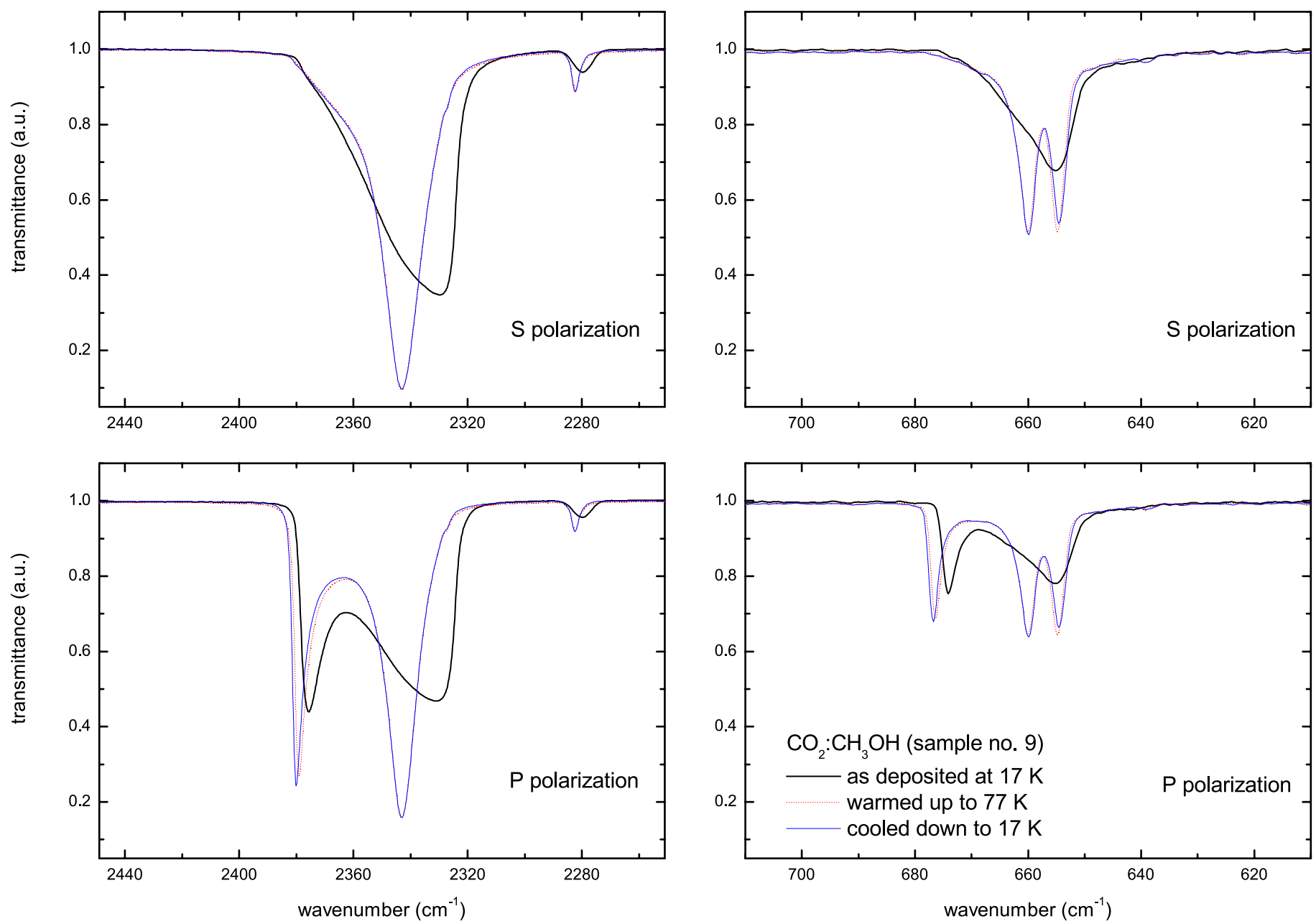

Fig. 8. Transmittance spectra of sample No. $9\left(\mathrm{CO}_{2}: \mathrm{CH}_{3} \mathrm{OH}=11: 1\right.$ mixture) in the $2450-2250 \mathrm{~cm}^{-1}$ spectral region (left-hand panels) and in the $710-610 \mathrm{~cm}^{-1}$ spectral region (right-hand panels). Spectra are acquired after sample deposition at $17 \mathrm{~K}$, after thermal annealing to $77 \mathrm{~K}$ and after cooling down to $17 \mathrm{~K}$.

in more diluted mixtures (such as the $\mathrm{H}_{2} \mathrm{O}: \mathrm{CO}_{2} \sim 1: 10$ mixture considered here). As shown in Fig. 5 the spectrum of a $\mathrm{CO}_{2}: \mathrm{H}_{2} \mathrm{O}=12: 1$ mixture does not show the band due to polymeric water at $3300 \mathrm{~cm}^{-1}$. This evidence is consistent with the results reported by Öberg et al. (2007).

Gerakines \& Hudson (2015) have performed their experiments in a high vacuum chamber (base pressure $10^{-7}-10^{-8}$ Torr). As reported in their manuscript, "the chief contaminant seen was residual $\mathrm{H}_{2} \mathrm{O}$ from the $\mathrm{CO}_{2}$ reagents and possibly from the vacuum system. Trace amounts of $\mathrm{H}_{2} \mathrm{O}$ gave weak IR peaks $(<0.01$ absorbance units in all cases) in the $3700-3500$ and $1600 \mathrm{~cm}^{-1}$ regions". The deposition rate used was $0.1 \mu \mathrm{m} / \mathrm{h}$. The substrate temperature was $10 \mathrm{~K}$. In those experimental conditions they have not observed the double peak of the bending mode profile in the spectrum of pure solid $\mathrm{CO}_{2}$. When the deposition rate was doubled (i.e. about $0.2 \mu \mathrm{m} / \mathrm{h}$ ) the double peak has been observed. Gerakines \& Hudson (2015) have interpreted these experimental results as due to amorphous (slow deposition rate) and crystalline (fast deposition rate) samples. On the basis of the experimental results reported in the present manuscript, the results of Gerakines \& Hudson (2015) could be interpreted as due to a higher presence of water contamination in the sample obtained with a slow deposition rate. In fact when the deposition rate is slowed down the relative contribution of the background residual gas (mainly $\mathrm{H}_{2} \mathrm{O}$ ) increases.
Here we presented the spectrum of a sample obtained with a deposition rate of $0.065 \mu \mathrm{m} / \mathrm{h}$ (sample No. 2), that is about half the slow deposition rate adopted by Gerakines \& Hudson (2015). As shown in Fig. 4 the profile of the $\mathrm{CO}_{2}$ bending mode shows the double peak. An even lower deposition rate (about $0.03 \mu \mathrm{m} / \mathrm{h}$ ) was adopted by Escribano et al. (2013) who have observed the double peak of the bending mode band ${ }^{2}$. We also present the spectra of two $\mathrm{CO}_{2}: \mathrm{H}_{2} \mathrm{O}=12: 1$ mixtures obtained with a deposition rate of $0.067 \mu \mathrm{m} / \mathrm{h}$ (sample No. 6) and $0.950 \mu \mathrm{m} / \mathrm{h}$ (sample No. 7), respectively. Both spectra (Fig. 4) do not show the double peak of the bending mode. Hence the disappearance of the double peak observed in the bending mode can be ascribed to the presence of $\mathrm{H}_{2} \mathrm{O}$ contamination independently of the deposition rate.

Figures 8-10 show the modifications observed in the profile of the asymmetric stretching mode and bending mode bands after warm up. The comparison between the results reported in Figs. 9 and 10 indicates that the structure of the $\mathrm{CO}_{2}$ sample deposited at $17 \mathrm{~K}$ is different from the structure of the sample deposited at $70 \mathrm{~K}$. Furthermore, the results reported in Fig. 8 are very similar to the results reported by Gerakines \& Hudson (2015) in their Fig. 2. In their work Gerakines \& Hudson (2015)

2 The deposition rate in units of $\mu \mathrm{m} / \mathrm{h}$ has been obtained from the deposition rate of $0.014 \mathrm{ML} / \mathrm{s}$ reported by the authors, assuming a density of $1.17 \mathrm{~g} \mathrm{~cm}^{-3}$ (this work). 
A\&A 608, A81 (2017)
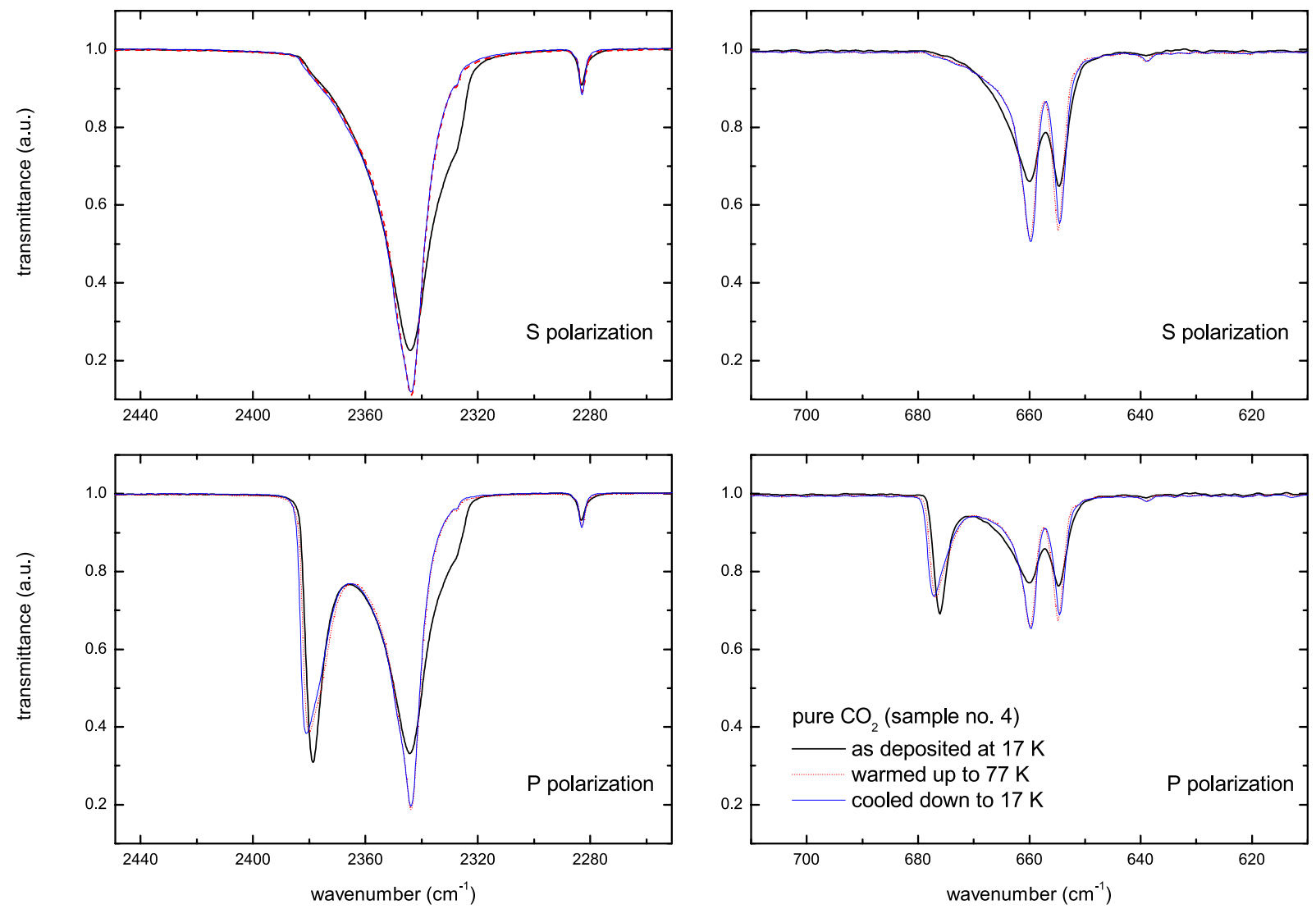

Fig. 9. Transmittance spectra of pure $\mathrm{CO}_{2}$ (sample No. 4) in the $2450-2250 \mathrm{~cm}^{-1}$ spectral region (left-hand panels) and in the $710-610 \mathrm{~cm}^{-1}$ spectral region (right-hand panels). Spectra are acquired after sample deposition at $17 \mathrm{~K}$, after thermal annealing to $77 \mathrm{~K}$ and after cooling down to $17 \mathrm{~K}$.
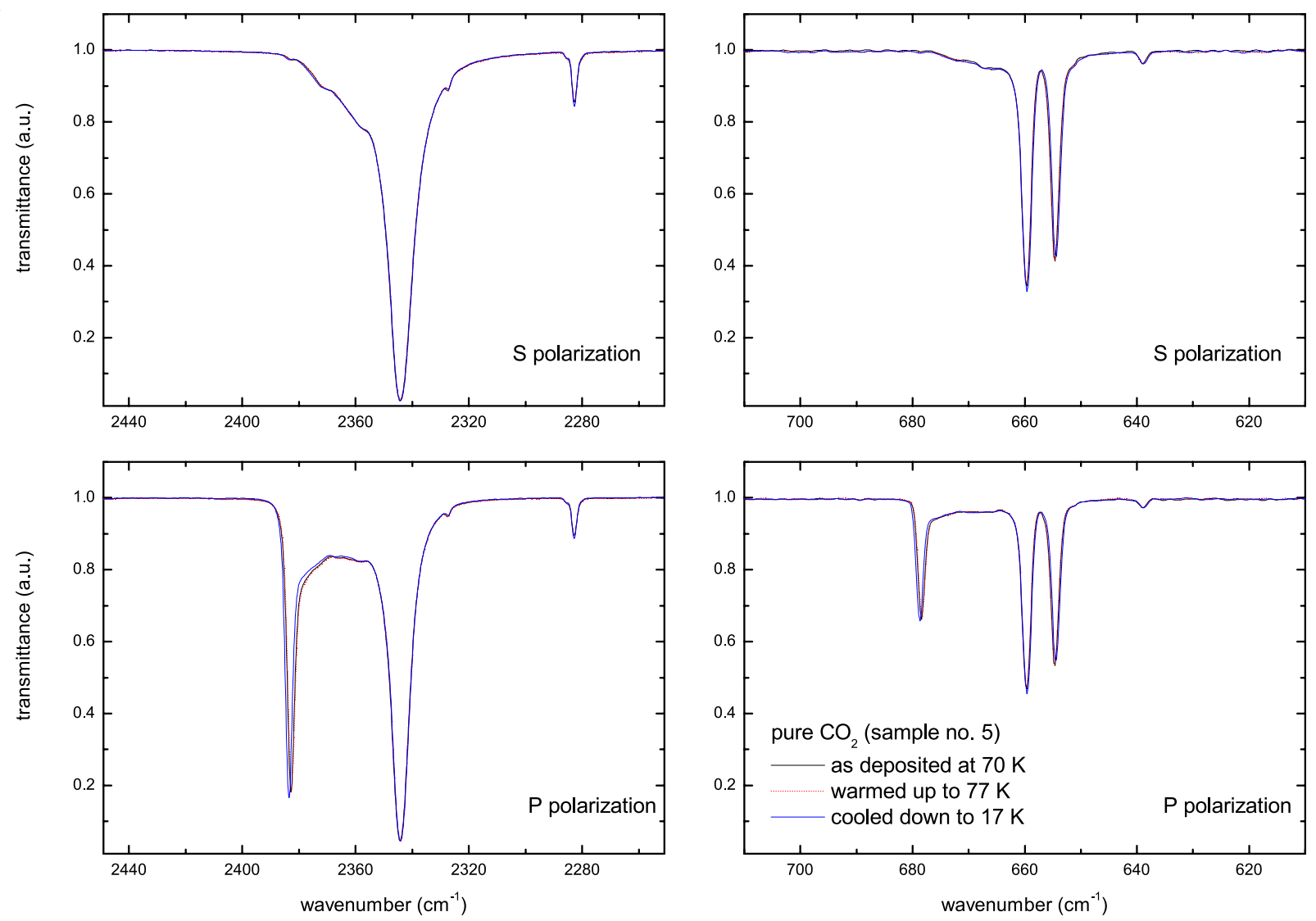

Fig. 10. Transmittance spectra of pure $\mathrm{CO}_{2}$ (sample No. 5) in the $2450-2250 \mathrm{~cm}^{-1}$ spectral region (left-hand panels) and in the $710-610 \mathrm{~cm}^{-1}$ spectral region (right-hand panels). Spectra are acquired after sample deposition at $70 \mathrm{~K}$, after thermal annealing to $77 \mathrm{~K}$ and after cooling down to $17 \mathrm{~K}$. 
have assumed that they deposited an amorphous $\mathrm{CO}_{2}$ sample that crystallizes after warm up. On the basis of the results reported in the present manuscript the comparison between the two figures indicates that whichever polar species is co-deposited with $\mathrm{CO}_{2}$ (either $\mathrm{H}_{2} \mathrm{O}$ or $\mathrm{CH}_{3} \mathrm{OH}$ ) the behaviour of the bands profile after warm up is the same.

A theoretical interpretation of the experimental results presented in this manuscript is beyond the aim of this work. The double peak observed in the profile of the bending mode band in crystalline $\mathrm{CO}_{2}$ samples is generally ascribed to the Davydov splitting (e.g. Pontoppidan et al. 2008; Isokoski et al. 2013; Cooke et al. 2016). The Davydov splitting (factor-group splitting) is the splitting of bands in the electronic or vibrational spectra of crystals due to the presence of more than one (interacting) equivalent molecular entity in the unit cell. This splitting is then not expected in amorphous disordered samples. Several studies in the field of organic semiconductors have demonstrated that amorphous solids show site splitting analogous to crystal Davydov splitting and that homo-dimers show the Davydov splitting (e.g. Jankowlak et al. 1983; Ottiger et al. 2015). Other studies in the field of atmospheric physics have shown that in a $\mathrm{CO}_{2}$ monomer, the $v_{2}$ bending mode is doubly degenerate while in a dimer, this mode splits into four vibrations. Of these, two vibrations, one in-plane and one out-of-plane, are active in infrared absorption (Vigasin et al. 2000). Following these results we suggest that during vapor deposition of pure $\mathrm{CO}_{2}$ samples the formation of dimers takes place, while when a small amount of a polar species (such as $\mathrm{H}_{2} \mathrm{O}$ and $\mathrm{CH}_{3} \mathrm{OH}$ ) is co-deposited with $\mathrm{CO}_{2}$ the formation of dimers is inhibited. Furthermore, the annealing experiments suggest that the dimers formed during deposition at low temperature are randomly oriented while a more ordered structure is obtained after warm up. This hypothesis is also consistent with the detection of the Fermi resonance features in dimers (e.g. Gómez Castaño et al. 2008) but not in crystalline samples (Falk 1987; Sivaraman et al. 2013; Gerakines \& Hudson 2015).

In summary we have found that, within experimental uncertainties, in UHV conditions, the profile of the $\mathrm{CO}_{2}$ bands in pure solid samples does not depend on the deposition rate or the sample thickness in the ranges investigated. In all cases the bending mode band profile shows a double peak (at 660 and $655 \mathrm{~cm}^{-1}$ ). The spectra of these samples show the Fermi resonance features that cannot be active in crystalline samples. On the other hand when a small fraction of a polar species (such as $\mathrm{H}_{2} \mathrm{O}$ and $\mathrm{CH}_{3} \mathrm{OH}$ ) is co-deposited with $\mathrm{CO}_{2}$ the double peak is not observed. Our experimental results indicate that the presence of the double peak in the profile of the $\mathrm{CO}_{2}$ bending mode is not an indication of a crystalline structure of the solid sample and these results do not exclude that amorphous solid $\mathrm{CO}_{2}$ is present in space.

Acknowledgements. The authors are grateful to Sergio Ioppolo for stimulating discussions on this work. This research has been partially supported by the Italian Ministero dell'Istruzione, dell'Università e della Ricerca through the grant Progetti Premiali 2012-iALMA (CUP C52I13000140001).

\section{References}

Baratta, G. A., \& Palumbo, M. E. 1998, J. Opt. Soc. Am. A, 15, 3076 Baratta, G. A., Palumbo, M. E., \& Strazzulla, G. 2000, A\&A, 357, 1045 Boogert, A. C. A., Gerakines, P. A., \& Whittet, D. C. B. 2015, ARA\&A, 53, 541 Cooke, I. R., Fayolle, E. C., \& Öberg, K. I. 2016, ApJ, 832, 5

Dartois, E., Demyk, K., d'Hendecourt, L. B., \& Ehrenfreund, P. 1999, A\&A, 351, 1066

Dohnálek, Z., Kimmel, G. A., Ayotte, P., Smith, R. S., \& Kay, B. D. 2003, J. Chem. Phys., 118, 364

Ehrenfreund, P., Boogert, A. C. A., Gerakines, P. A., Tielens, A. G. G. M., \& van Dishoeck, E. F. 1997a, A\&A, 328, 649

Ehrenfreund, P., d'Hendecourt, L., Dartois, E., et al. 1997b, Icarus, 130, 1

Escribano, R. M., Muñoz Caro, G. M., Cruz-Diaz, G. A., Rodríguez-Lazcano, Y., \& Maté, B. 2013, PNAS, 110, 12899

Falk, M. 1987, J. Chem. Phys., 86, 560

Fulvio, D., Sivaraman, B., Baratta, G. A., Palumbo, M. E., \& Mason, N. J. 2009, Spectrochimica Acta Part A, 72, 1007

Gerakines, P. A., \& Hudson, R. L. 2015, ApJ, 808, L40

Gerakines, P. A., Schutte, W. A., Greenberg, J. M., \& van Dishoeck, E. F. 1995, A\&A, 296, 810

Gerakines, P. A., Whittet, D. C. B., Ehrenfreund, P., et al. 1999, ApJ, 522, 357

Gómez Castaño, J. A., Fantoni, A., \& Romano, R. M. 2008, J. Mol. Struct., 881, 68

Hagen, W., Tielens, A. G. G. M., \& Greenberg, J. M. 1983, A\&AS, 51, 389

Hudgins, D. M., Sandford, S. A., Allamandola, L. J., \& Tielens, A. G. G. M. 1993, ApJS, 86, 713

Ioppolo, S., Palumbo, M. E., Baratta G. A., \& Mennella, V. 2009, A\&A, 493, 1017

Ioppolo, S., Sangiorgio, I., Baratta G. A., \& Palumbo, M. E. 2013, A\&A, 554, A34

Isokoski, K., Poteet, C. A., \& Linnartz, H. 2013, A\&A, 555, A85

Jankowlak, R., Rockwitz, K. D., \& Bässler, H. 1983, J. Phys. Chem., 87, 552

Jenniskens, P., \& Blake, D. 1994, Science, 265, 753

Jiang, G. J., Person, W. B., \& Brown, K. G. 1975, J. Chem. Phys., 62, 1201

Kimmel, G. A., Stevenson, K. P., Dohnálek, Z., Smith, R. S., \& Kay, B. D. 2001a, J. Chem. Phys., 114, 5284

Kimmel, G. A., Dohnálek, Z., Stevenson, K. P., Smith, R. S., \& Kay, B. D. 2001b, J. Chem. Phys., 114, 5295

Leto, G., \& Baratta, G. A., 2003, A\&A, 397, 7

Loeffler, M. J., Moore, M. H., \& Gerakines, P. A. 2016, ApJ, 827, 98

Modica, P., \& Palumbo, M. E. 2010, A\&A, 519, A22

Nummelin, A., Whittet, D. C. B., Gibb, E. L., Gerakines, P. A., \& Chiar, J. E. 2001, ApJ, 558, 185

Öberg, K., Fraser, H. J., Boogert, A. C. A., et al. 2007, A\&A, 462, 1187

Ottiger, P., Köpper, H., \& Leutwyler, S. 2015, Chem. Sci., 6, 6059

Palumbo, M. E., \& Baratta, G. A. 2000, A\&A, 361, 298

Palumbo, M. E., Baratta, G. A., Brucato, J. R., et al. 1998, A\&A, 334, 247

Palumbo, M. E., Castorina, A. C., \& Strazzulla, G. 1999, A\&A, 342, 551

Palumbo, M. E., Baratta, G. A., Collings, M. P., \& McCoustra, M. R. S. 2006, Phys. Chem. Chem. Phys., 8, 279

Polyanskiy, M. N. 2017, Refractive index database, https:// refractiveindex. info, accessed on 2017-03-27

Pontoppidan, K. M., Boogert, A. C. A., Fraser, H. J., et al. 2008, ApJ, 678, 1005

Sandford, S. A., \& Allamandola, L. J. 1990, ApJ, 355, 357

Satorre, M. A., Domingo, M., Millán, C., et al. 2008, Planet. Space Sci., 56, 1748

Sivaraman, B., Raja Sekhar, B. N., Fulvio, D., et al. 2013, J. Chem. Phys., 139, 074706

Urso, R. G., Sciré, C., Baratta, G. A., Compagnini, G., \& Palumbo, M. E. 2016, A\&A, 594, A80

Vigasin, A. A., Schriver-Mazzuoli, L., \& Schriver, A. 2000, J. Phys. Chem. A, 104, 5451

Wood, B. E., \& Roux, J. A. 1982, J. Opt. Soc. Am., 72, 720

Yamada, H., \& Person, W. B. 1964, J. Chem. Phys., 41, 2478 